\title{
Pattern of Epithelial Cell Abnormalities on Cervical Papanicolaou Smears in Hospital of North India: A Retrospective Study
}

\author{
Udita Singhal, Sangeeta Lamba, Uma Kumar* and Annu Nanda \\ Dept of Pathology, ESI Hospital, Rohini, Delhi(India)
}

\begin{abstract}
Introduction: Cervical cancer is the most common cancer of the female genital tract. India accounts for $25 \%$ of the cervical cancer deaths and the incidence is about $23.29 \%$. Pap smear test is considered to be most important test for screening of cervical cancers and is regarded as gold standard for screening program.

Materials and Methods: A retrospective study was carried in Department of Pathology of a Hospital of North India, from June 2014 to Jan2017.Total of 1534 samples were screened.We followedThe Bethesda system2014 for reporting thePap smears.

Results: Out of 1534 samples, 4.8\%were unsatisfactory, 90.6\%were NILM, 1.4\%were ASCUS,0.8\%each were LSIL,HSIL,and Squamous Cell Carcinoma $0.26 \%$ each were AGCUS and ASCH.The commonest age group affected was $30-50$ years.

Conclusion: Pap Screening should focus on the peri -menopausal and the post- menopausal Group as in our studywe found thatmost of the patients belongedto this age group.
\end{abstract}

Keywords: Pap Smear Screening, Epithelial Cell Abnormalities, Cancer Cervix, The Bethesda System

\section{Introduction}

Cervical cancer is the most common cancer of the female genital tract .India accounts for $25 \%$ of the cervical cancer deaths and the incidence is about $23.29 \%,{ }^{[1]}$. Cervical cancer now ranks number two as the cause of female cancer in India, first being carcinoma of the breast, ${ }^{[2]}$.The etiological factors of carcinoma of the uterine cervix are early age of marriage, multi parity, early age of sexual intercourse ,low socioeconomic status, ignorance and illiteracy, viruses chiefly HPV, HIV, HSV.$^{[3]}$ Epidemiological studies on cancer cervix suggest that it is very suitable target for primary prevention of the disease by screening ${ }^{[4]}$. There are various screening test for cervical cancer like Pap smear, Liquid based cytology, Visual inspection of the cervix after application of Lugol's iodine , acetic acid application, speculoscopy and cervicography. ${ }^{[5]}$ Pap smear test is considered to be most important test for cervical cancers screening programs. Thus we undertook the present study to study the pattern of epithelial cell abnormalities and cancer cervix and also to assess the age group in which the screening program should be concentrated to bring about a reduction in the incidence of cancer cervix.

\section{Materials and Methods}

A retrospective study was carried in Department of Pathology of a hospital of North Delhi, from June 2014 to
Jan2017. 1534 smears were screened. The patients were in age group ranging from 20 to 80 years, with various complaints of vaginal discharge, abnormal bleeding, bleeding after menopause, PID, unhealthy looking cervix, erosion cervix etc. Patients posted for hysterectomy and vault smears, patients receiving chemotherapy, radiotherapy and known cases of carcinoma cervix were excluded from the study. Smears were taken by senior residents and/ or specialists in the gynecology OPD using modified Ayres spatula. It was inserted and then rotated full 360 degree over the cervix. Both endocervix and ectocervix were sampled. The material obtained was quickly smeared on the glass slides, labelled appropriately and fixed in 95\%ethyl alcohol, stained by Papanicolaou stain by the lab technician. The slides were mounted with DPX; and screened by cytopathologist. The Bethesda system 2014 was followed for reporting of Pap smears by the cytopathologists.

\section{Results}

Our study showed that $95.2 \%$ (1391) smears were benign (NILM) and $4.72 \%$ (69) were abnormal smears. 4.8\% (74) samples were found to be unsatisfactory (Table 1). Among unsatisfactory smears 30 out of $74(40.5 \%)$ samples belonged to age group of 50-59 and 40-49 years of age (Table 3). 
Among the NILM group 69.4\% (965) were NOS, $6.4 \%$ (62) showed reactive atypia, non- specific inflammation was seen in $81.6 \%$ (788), while atrophy was reported in 11.9\% (115). (Table2).

Among the specific infections bacterial vaginosis was most common, seen in 264 (18.9\%), Candida in 137(9.8\%), Trichomonas was reported in $21(1.4 \%)$ cases only. Trichomonas with Leptothrix seen in 2 cases $(0.14 \%)$ and Candida with Leptothrix, and only Actinomyces infection in 1 each constituting $0.07 \%$ each.

A total number of 69 cases revealed epithelial abnormalities. The age of the patients with an abnormal smear was Table. 1 Pap Smear result of the study group.

\begin{tabular}{|l|c|c|}
\hline Pap Result & No. Of cases & \% of total no. of smears \\
\hline UNSATISFACTORY & 74 & 4.8 \\
\hline NILM & 1391 & 95.21 \\
\hline ASCUS & 22 & 1.5 \\
\hline ASCH & 04 & 0.27 \\
\hline AGC & 04 & 0.27 \\
\hline LSIL & 13 & 0.89 \\
\hline HSIL & 13 & 0.89 \\
\hline SCC & 13 & 0.89 \\
\hline Total & 1534 & 100 \\
\hline
\end{tabular}

Table 2: Non neoplastic cytological diagnosis in pap smear.

\begin{tabular}{|c|c|c|}
\hline Pap Result & No. of cases & $\%$ of cases \\
\hline $\begin{array}{l}\text { NOS } \\
\text { Reactive Atypia =6.4\% } \\
\text { Non Specific Inflammtion =81.6\% } \\
\text { Atrophy }=11.9 \%\end{array}$ & 965 & $69.4 \%$ \\
\hline CANDIDA & 137 & $9.8 \%$ \\
\hline B.VAGINOSIS & 264 & 18.95 \\
\hline TRICHOMONAS.VAGINALIS & 21 & $1.4 \%$ \\
\hline ACTINOMYCES & 1 & $.07 \%$ \\
\hline CANDIDAAND LEPTOTHRIX & 1 & $.07 \%$ \\
\hline TRICHOMONAS AND LEPTOTHRIX & 2 & $.14 \%$ \\
\hline
\end{tabular}

Table 3: Cervical epithelial abnormalities in relation to age.

\begin{tabular}{|c|c|c|c|c|c|c|c|c|c|}
\hline $\begin{array}{l}\text { AGE } \\
\text { GROUP }\end{array}$ & $\begin{array}{c}\text { UN- } \\
\text { SATISFACTORY }\end{array}$ & $\%$ & ASCUS & LSIL & HSIL & SCC & AGC & ASCH $\mid \%$ & $\%$ \\
\hline $20-29$ & 12 & 16.21 & 00 & 4 & 0 & 2 & 0 & 00 & 8.69 \\
\hline $30-39$ & 15 & 20.27 & 03 & 3 & 2 & 0 & 2 & 00 & 14.49 \\
\hline $40-49$ & 17 & 22.97 & 06 & 1 & 4 & 1 & 2 & 03 & 24.63 \\
\hline $50-59$ & 16 & 21.62 & 09 & 3 & 4 & 5 & 0 & 01 & 31.88 \\
\hline $60-69$ & 14 & 18.91 & 04 & 2 & 3 & 2 & 0 & 0 & 15.94 \\
\hline $70-79$ & 0 & 00 & 00 & 0 & 0 & 2 & 0 & 0 & 2.89 \\
\hline TOTAL & 74 & $100 \%$ & $\begin{array}{c}22 \\
(31.88 \%)\end{array}$ & $\begin{array}{c}13 \\
(18.84 \%)\end{array}$ & $\begin{array}{c}13 \\
(18.84 \%)\end{array}$ & $\begin{array}{c}13 \\
(18.84 \%)\end{array}$ & $\begin{array}{c}4 \\
(5.79 \%)\end{array}$ & $\begin{array}{c}4 \\
(5.79 \%)\end{array}$ & $\begin{array}{c}6.79 \\
(100 \%)\end{array}$ \\
\hline
\end{tabular}

between 20-79 years with the mean age being 52.12 years (Table 3). The most common epithelial abnormality was ASCUS (22 cases) with majority belonging to 30-69 age group. LSIL, HSIL and squamous cell carcinoma were seen in 13 patients each, accounting for $0.89 \%$, collectively contributing to $2.67 \%$. ASCH and AGC were seen in 4 cases each amounting to $0.27 \%$ each

\section{Discussion}

It is known that the burden of the cervical cancer has declined after the introduction of the screening programmes. ${ }^{[6,7,8]}$ Data from hospital based studies is an important tool to assess the effectiveness of the screening programs. It 
Table 4: Results of Pap Smear screening in various parts of India.

\begin{tabular}{|c|c|c|c|c|c|c|c|c|c|}
\hline Ref. & 28,29 & 5 & 30,31 & 32 & 33 & 34 & 25 & 35 & \\
\hline Year & 2009 & 2011 & 2012 & 2013 & 2014 & 2015 & 2016 & 2017 & 2017 \\
\hline Place & $\begin{array}{c}\text { Hyderabad } \\
\text { /Lucknow }\end{array}$ & Gujarat & $\begin{array}{c}\text { Punjab } \\
\text { /Guwahati }\end{array}$ & $\begin{array}{c}\text { Uttar } \\
\text { Pradesh }\end{array}$ & $\begin{array}{l}\text { Mangalore } \\
\text { /Ahmedabad }\end{array}$ & Bhopal & Kerala & Mangalore & Delhi \\
\hline $\begin{array}{l}\text { Sample } \\
\text { size }\end{array}$ & $6010 / 36484$ & 995 & $300 / 242$ & 4703 & $1000 / 36740$ & 1887 & 2028 & 308 & 1534 \\
\hline Author & $\begin{array}{l}\text { MulayK } \\
\text { /MisraJS }\end{array}$ & Patel M & $\begin{array}{c}\text { Bal MS } \\
\text { Usha } \\
\text { Sarma }\end{array}$ & $\begin{array}{l}\text { Kamna } \\
\text { Gupta }\end{array}$ & $\begin{array}{c}\text { Preetha } \\
\text { George } \\
\text { /Sadhna } \\
\text { Kothari }\end{array}$ & $\begin{array}{l}\text { Geeth } \\
\text { Katheit }\end{array}$ & $\begin{array}{l}\text { Geethu } \\
\text { G Nair }\end{array}$ & $\begin{array}{c}\text { Shashidhar } \\
\text { MR }\end{array}$ & \\
\hline Prevalence & $1.39 / 7.8 \%$ & 5.52 & $5 / 11.95$ & 3.2 & $3.5 / 1.32$ & 1.32 & 2.42 & & $4.9 \%$ \\
\hline ASCUS & $0.64 /-$ & 4.1 & $0.3 / 1.32$ & 0.52 & $0.3 / 0.11$ & 0.48 & 0.15 & 1.62 & 1.5 \\
\hline LSIL & $0.22 / 5.5$ & 0.1 & $2.7 / 3.53$ & 1.36 & $2.0 / 0.83$ & 0.42 & 1.58 & 0.64 & 0.89 \\
\hline HSIL & $0.16 / 1.6$ & 0.1 & $0.7 / 3.53$ & 0.91 & $0.9 / 0.31$ & 0.16 & 0.49 & 0.00 & 0.89 \\
\hline SCC & $.06 / 0.6$ & 0.7 & $1.3 / 3.53$ & 0.28 & $0.3 / 0.05$ & 0.05 & 0.20 & 0.64 & 0.89 \\
\hline
\end{tabular}

also helps to reassess the ongoing programs of screening and develop strategies for implementation, targeting the most vulnerable group. Such data is used for reference and research purposes also. Therefore we carried out a retrospective study in our hospital to find out the pattern of epithelial abnormalities and the target age group where the screening programs should be concentrated.

The Bethesda System for reporting the results of cervical cytology was developed as a uniform system of terminology that aims to provide clear guidelines for clinical management. Pap smear reporting by the use of TBS 2014 has unified various overlapping terminologies and includes specific statements. $[9,10]$ Specimen type indicates a conventional smear or a liquid based preparation. Evaluation of specimen adequacy is considered by many to be the most important quality assurance component of TBS. Though the presence of transformation zone is not necessary for adequacy, but its presence or absence should be noted as it may be a quality assurance measure. NILM category includes spectrum of non- neoplastic changes protective and reactive responses to inflammation, hormonal changes, infectious organisms. The (ASC) Atypical Squamous Cells, is now separated in two broad categories ASCUS and ASC-H reflecting the 2 tier reporting for HPV related squamous lesions. The lesions associated with persistent HPV are associated with precancer or invasive cancer, LSIL encompasses mild dysplasia and CIN 1 and HSIL with moderate and severe dysplasia, CIN 2, CIN3.In our study we have adopted TBS2014 for reporting pap smears ${ }^{[10]}$.

The most common cause of unsatisfactory smears was scant cellularity $68 \mathrm{n}(91.89 \%)$, mainly blood in $2(2.70 \%)$ and $4(5.41 \%)$ smears were obscured by dense inflammation. In our study 30 out of $74(40.5 \%)$ samples belonged to age group of 50 to 59and 40-49 years of age. Higher age group especially post menopause contributes largely to unsatisfactory smears due to tissue atrophy. Both gynecologists and pathologists should be aware of this and must apply extra efforts to collect the sample with optimal techniques and also counsel the patient if a repeat sample is required. ${ }^{[11]}$ Many studies recommend second sampling in this age group, extra processing of the smears in the lab and even HPV testing. ${ }^{[11]}$ In a low resource setting like ours we did not repeat the sample or reprocessed the samples, though in our study the percentage of abnormal smears was highest in this age group.

Different studies have shown a wide range of prevalence of epithelial cell abnormalities ranging from $1.14 \%$ in Nepal, ${ }^{[12]}$ to $14.52 \%$ in Iran. ${ }^{[13]}$.In our study we found them to be $4.72 \%$. ASCUS was the commonest accounting for $1.5 \%$ cases, the commonest age group in which it was reported was 50-59 years of age. ASCUS progresses to LSIL, HSIL, SCC. AGUS progresses to adenocarcinoma. ${ }^{[14]}$

Comparisons between the labs have shown that diagnostic frequency of ASCUS is variable ranging from $1.6 \%$ to $9 \%$. 
${ }^{[15,16]}$ Gerber et al detected ASCUS in 5\% (1387) out of total 29,827 patients in their study. Guerreni et al reclassified 107 patients with a diagnosis of ASCUS and found 78.5\% of them to be reactive and $21.5 \%$ to be probably neoplastic. The absence of well-defined criteria, as well as subjectivity of the diagnosis may account for the variation. ${ }^{[17]}$ In our study of 22 cases, 12 came for follow up, 8 came out to be NILM, 3 showed reactive atypia and 1 was labelled LSIL. The criterion for ASCUS may differ subtly among labs, reflecting differences in staining and techniques for slide preparation.. ${ }^{[10]}$ According to Barccelos $\mathrm{M}$ et al who performed a clinical study on ASCUS as per The Bethesda classification and association with HPV; they observed that the number of cytological diagnoses of ASCUS in their service was equivalent to 1.3 times the frequency of LSIL ${ }^{[18]}$.In majority of the US labs, the ratio between ASCUS and LSIL is in the range of $2 ; 1^{[19]}$.Nascimento, et al used ASCUS/SIL ratio for cytopathologists as quality control measure. The value of ASCUS/SIL ratio was calculated every 6months for 3.5 years and a feedback was provided to 10 cytopathologists. When they analyzed the initial and final ratio for individual cytopathologists and also for entire group, the ratio showed a downward trend from 2.05 to $1.73^{[20]}$. Juskeviious $\mathrm{R}$, et al analyzed the factors that influence the ASUS/SIL ratio of pathologists. They provided a confidential feedback every six months and also introduced thin layer technology as an alternative to conventional smears. They found a significant reduction in the mean ASUS/SIL ratio, which declined from 2.92 to $1.87^{[21]}$. In present study, 22 cases of ASCUS were reported which is less than 2 times that of LSIL (13 Cases).

LSIL, HSIL and squamous cell carcinoma were seen in 13patients each, accounting for $0.89 \%$, Collectively contributing to $2.67 \%$. ASCH and AGC was seen in 4 cases each amounting to $0.27 \%$ each. Nuclear abnormalities are required to make a diagnosis of LSIL. Cytopathic effect of HPV in form of peri -nuclear cytoplasmic halo is not a prerequisite for its diagnosis. According to Stoler $\mathrm{MH}$ et al (ALTS) Group inter observer reproducibility of LSIL on cytology is much more than LSIL on histology. ${ }^{[22]}$ Since the HPV Status of our patients was unknown, a repeat cytology was recommended in 12 months as per ASCCP management guidelines 2012. ${ }^{[23]}$ In our study HSIL and invasive carcinoma was $0.89 \%$ of total epithelial lesions. Except for Pakistan, South Africa and Bangladesh prevalence of HSIL is less than $1 \%$ as found in our study also. ${ }^{[24]}$

In our study, epithelial abnormality was more prevalent in post-menopausal group (50-59) with $31.8 \%$ followed by $24.6 \%$ in 40-49 years age group. This is slightly lower than studies by Bukhari et al and Geethu Nair et al in which $44.9 \%$ cases belonged to this age group ${ }^{[25-26]}$. (Table 4$)$. This fact strongly highlights the need to create awareness about pap screening programs in this age group and to motivate them to attend cervical cancer screening programs. In a study conducted by Naseema et al among health care workers in a government medical college Calicut shows $46.7 \%$ of them had never heard of the pap smears ,and $30.7 \%$ had undergone pap only once. ${ }^{[27]}$

Limitations of the study were lack of follow up of majority of the patients. HPV -DNA testing could not be done on the patients, Liquid based cytology, though can have an impact on reducing the number of unsatisfactory smears, but is not -feasible in our set up, owing to cost constraints.

\section{Conclusions}

Cervical cancer is a leading cause of death in India. Pap smear is a very simple, cost effective method to detect cervical epithelial cell abnormalities. Hence as a routine procedure all females above 40 should undergo this test as per WHO guidelines. It should especially focus on the peri -menopausal and the post- menopausal group as in our study most of the patients belong to this age group. Our study supports other studies for the need to have more awareness programs through Pap smear screening camps, female health fairs, linking ADHAAR number and sending educational messages for awareness, motivation and better follow up.

Larger studies are required to know the pattern of abnormalities and also study into the socio- cultural, economic as well as psychological aspects which prevent the females from attending the Pap screening programs.

\section{References}

1. International Agency for Research on Cancer and World Health Organization [Internet]. GLOBOCAN 2012: Estimated cancer Incidence, mortality and prevalence worldwide in 2012.

2. ICO Information Centre on HPV and Cancer. (Summary Report 2014.08.22). Human Papillomavirus and related Diseases in India. Human Papillomavirus and Related Diseases Report.

3. Park K, Park's Textbook of Preventive and Social Medicine .24th edition. Banarsidas Bhanot Publishers, (2017).

4. Shanta V, Krishnamurthi S, Gajalakshmi CK, Swaminathan R, Ravichandran K. Epidemiology of Cancer of the Cervix: Global and national perspective. Journal of Indian Medical Association.2000, 98(2):49-52 
5. Patel MM, Pandya AN, Modi J. Cervical Pap smear study and its utility in cancer screening, to specify the strategy for cervical cancer control. Natl J Com Med 2011; 1:49- 51.

6. Cheryl LR, Clair WM, Kevin R et al. prevention of cervical cancer. Critical review in Oncology / Hematology; 2000: 33: 169-185.

7. Ali F, Kuelker R, Wassie B. Understanding cervical cancer in the context of developing countries. Ann Trop Med Public Health 2012; 5:3-15.

8. Denny L. The Prevention of Cervical Cancer in developing countries. British Journal of Obstetrics and Gynecology 2005; 112:1204-12.

9. Department of Cytology and Gynecological Pathology, Postgraduate Institute of Medical Education, and Research, Chandigarh, India. Guidelines for Cervical Cancer Screening Program.

10. Solomon D, Nayar R, editors. The Bethesda System for reporting cervical cytology: defintions, criteria, and explanatory notes. New York: Springer-Verlag; 2004.

11. Nayar R, Wilbur DC, editors. The Bethesda System for reporting cervical cytology: defintions, criteria, and explanatory notes. Springer, 2015.

12. Paulin H, Geldenhuys L, Naugler C. Predictors of an Unsatisfactory Conventional Cervical Cytology Smear. Journal Obstet Gynaecol Can 2011; 33(7):725-728

13. Marahatta R, Bhattarai S. Value of conventional cervical cytology as a screening test for cervical cancer. Nepal Medical College Journal. 2013; 15(2) 223.

14. Afrakhteh M, Khodakarami N, Moradi A, Alavi E, Shirazi F H. A study of 13315 papanicolaou smear diagnoses in Shohada Hospital. Journal of Family Reproduction and Health 2007; 1:74-8.

15. Izabela T. Burja, Sophie K. Thompson. Atypical glandular cells of undetermined significance on cervical smears. Acta cytologica; vol.43, no. 3: 1999: 357-56.

16. Gerber S, De Grandi P, Petignat P. Colposcopic evaluation after a repeat atypical squamous cells of undetermined significance (ASCUS) smear. International Journal Gynaecol obstet. 2001; 75:251-255.

17. Guerrini L, Sama D, Visani M. Is it possible to define a better ASCUS class in cervicovaginal screening?" Acta Cytologica, Vol.45, no.4, pp.532-536, 2001.

18. The Bethesda System for Reporting Cervical Cytology. Definitions, Criteria and Explanatory Notes. Editors: Nayar Ritu, Wilbur, David (Eds).

19. Barcelos A, Michelin M, Adad S, Murta E. Atypical Squamous Cells Of Undetermined Significane: Bethesda Classification and Association with Human Papillomavirus. Infectious Diseases in Obstetrics and Gynecology. Volume2011(2011), Article ID 904674, 9pages
20. Emerging issues on HPV infections: from Science to Practice. Editor, Joseph Monsonego. Karger Medical and Scientific Publishers, Jan 2006.

21. Nasimento A, Cibas ES. The ASC/SIL Ratio for Cytopathologists as a Quality Control Measure. A Follow -up Study. American Journal of Pathology 2007; 128:653-656.

22. Juskevicius R, ZouKH, CibasES.An analysis of factors that influence the ASCUS/SIL ratio of pathologists. American Journal of Clinical Pathology. 2001;116(3):331-5

23. Stoler MH, Schiffman M; Atypical Squamous Cells of Undetermined Significance- Low-grade Squamous Intraepithelial Lesion Triage Study (ALTS) Group. JAMA.2001 Mar 21; 285(11):1500-5.

24. Massad L.S, Einstein M.H, Huh W.K., Katki H. A., Kinney W. K., Schiffman M., Solomon D, Wentzensen N., Lawson H. W. 2012 ASCCP Consensus Guidelines Conference. 2012updated consensus guidelines for the management of abnormal cervical cancer screening tests and cancer precursors. Obstet. Gynecol.2013; 121:829-846.

25. Geethu G. Nair et al Cytopathological pattern of cervical pap smears - a study among population of North Malabar in Kerala Indian Journal of Pathology and Oncology, OctoberDecember 2016;3(4);552-557.

26. Bukhari MH, Saba K, Qamar S, Majeed MM, Niazi S, Naeem S. Clinicopathological importance of Papanicolaou smears for the diagnosis of premalignant and malignant lesions of the cervix. Journal of Cytology 2012; 29:20-5.

27. Beevi NA, Sreenivas S. Awareness of cervical cancer and Pap smear and it's utilization among health care workers in medical college, Kozhikode. Journal of evidence based medicine and health care.2014; 1:12-7.

28. Mulay K, Swain M, Patra S, Gowrishankar S. A comparative study of cervical smears in an urban Hospital in India and a population-based screening program in Mauritius. Indian Journal of Pathology and Microbiology 2009; 52:34-7. 19

29. Misra JS, Srivastava S, Singh U, Srivastava AN. Risk factors and strategies for control of carcinoma cervix in India: hospital based cytological screening experience of 35 years. Indian Journal of Cancer 2009; 4:155-9.

30. Bal MS, Goyal R, Suri AK, Mohi MK. Detection of abnormal cervical cytology in Papanicolaou smears. Journal of Cytology. 2012; 29:45-7.

31. Sarma U, Mahanta J, Talukdar K. Pattern of Abnormal Cervical Cytology in women attending a Tertiary Hospital. International Journal of Scientific and Research Publications 2012; 2 :4pages.

32. Gupta K, Malik NP, Sharma VK, Verma N, Gupta A. Prevalence of cervical dysplasia in western Uttar Pradesh. Journal of Cytology 2013; 30:257-62. 
33. Kothari S, Gohel A, Dayal A, Shah R, Patel S. Pap smear - A tool for detection of cervical intraepithelial lesions in health checkup schemes: A study of 36,740 cases. International Journal of Research Medicine. 2014; 3:12-5.

34. Katheit G, Tiwari S. Cytological pattern and demographic determinants of cervical cytology (Papanicolaou smear) in a tertiary center of central India. European journal of biomedical \& pharmaceutical sciences 2015; 2:1402-9.

35. Shashidhar MR, Jayasheelan. Prevalence of cervical cancer and role of screening programs by PAP Smears. International Journal of Pathology, 2017; 1(2):32-36

*Corresponding author:

Dr Uma Kumar, Specialist Pathology, Employee’s State Insurance Hospital, Sector 15 Rohini, Delhi(India)-110085

Phone: +91 9968186177

Email: dr.uma.path@gmail.com

Financial or other Competing Interests: None. 